\title{
INVESTIGATION OF MECHANICAL PROPERTIES OF CRAB SHELL: A REVIEW
}

\author{
Kishore Kumar Gadgey ${ }^{1}$ and Dr. Amit Bahekar ${ }^{2}$
}

\begin{abstract}
The present review describes the development of investigations of mechanical properties of crab shell. The mechanical behavior of crab shell was investigated. There was low strain discontinuity in their bulk tensile stress-strain curves. The crab cuticle fails in an entirely brittle manner. The cutile of the crab is a composite material, the properties of which are closely analogous to those of pre-stressed concrete. The mechanical properties of the exoskeleton of the sheep crab (Loxorhynchus grandis) were investigated earlier. It was found that the crab exoskeleton is a natural composite consisting of highly mineralized chitin-protein fibers arranged in a twisted plywood pattern. It was observed that there is a high density of pore canal tubules in the direction normal to the surface. Tensile tests were carried out on wet and dry specimens in longitudinal as well as normal directions. Samples tested in the longitudinal direction showed a convex shape and no evidence of permanent deformation prior to failure, whereas samples tested in the normal orientation exhibited a concave shape. The results show that the composite is anisotropic in mechanical properties. Micro indentation was performed to measure the hardness through the thickness. It was found that the outer layer is two times harder than the inner layer.

Keywords - Mechanical Properties, Crab Shell, Cuticle, Exoskeleton
\end{abstract}

\section{INTRODUCTION}

Crab Shell is the second most common natural composite material in the world, and one of the most versatile. Very few mechanical studies have been made on the hard shells (solid cuticle) characteristic of the arthropod integument and it is therefore not yet possible to provide a general model for the mechanical behavior of the exoskeletons of this phylum. Arthropods are the largest animal phylum. They include the trilobites, chelicerates, myriapods, hexapods, and crustaceans. All arthropods are covered by an exoskeleton, which is periodically shed as the animal grows. The exoskeleton of arthropods consists mainly of chitin. In the case of crustaceans, there is a high degree of mineralization, typically calcium carbonate, which gives mechanical rigidity. The various studies carried out on insect solid cuticle[1-4] and prawn shells [5] indicate a number of similarities in the mechanical behaviour of insect and prawn solid cuticle as well as differences apparently due to the fact that the former are two-phase composite materials consisting of chitin fibres in a protein matrix while the latter include another phase, namely inorganic alts, resulting in a three-phase material. In the present review, the mechanical behavior of the solid cuticle of the crab, Scylla serrata, was investigated in order to determine their fracture behavior, microhardness properties and general mechanical behavior as composite materials. This crustacean

\footnotetext{
${ }^{1}$ Department of Mechanical Engineering Government Polytechnic College, Sanawad, M P, India

${ }^{2}$ Department of Mechanical Engineering Oriental University Indore, M P, India
} 
was also studied in order to define more closely what might be peculiarly crustacean (i.e. threephase dependent behavior) as opposed to insectan (i.e. two-phase behavior) and finally to provide additional evidence for generalizations about arthropod solid cuticle. The arthropod exoskeleton is multifunctional: it supports the body, resists mechanical loads, and provides environmental protection and resistance to desiccation [6-10]. The outermost region is the epicuticle, a thin, waxy layer which is the main waterproofing barrier. Beneath the epicuticle is the procuticle, the main structural part, which is primarily designed to resist mechanical loads. The procuticle is further divided into two parts, the exocuticle (outer) and the endocuticle (inner), which have similar composition and structure. The endocuticle makes up around 90 vol.\% of the exoskeleton. The exocuticle is stacked more densely than the endocuticle. The spacing between layers varies from species to species. Generally, the layer spacing in the endocuticle is about three times larger than that in the exocuticle [11]. Fig. 1a is a SEM micrograph showing the epicuticle, exocuticle, and endocuticle. A striking feature of arthropod exoskeletons is their welldefined hierarchical organization, which reveals different structural levels, as shown in Fig. $1 b$. At the molecular level, there are long-chain polysaccharide chitins that form fibrils, $3 \mathrm{~nm}$ in diameter and $300 \mathrm{~nm}$ in length. The fibrils are wrapped with proteins and assemble into fibers of about $60 \mathrm{~nm}$ in diameter. These fibers further assemble into bundles. The bundles then arrange themselves parallel to each other and form horizontal planes. These planes are stacked in a helicoid fashion, creating a twisted plywood structure. A stack of layers that have completed a 180_rotation is referred to as a Bouligand structure. These structures repeat to form the exocuticle and endocuticle [12-16]. The same Bouligand structure is also characteristic of collagen networks in compact bone, cellulose fibers in plant cell walls and other fibrous materials [17]. In crab exoskeletons, the minerals are in the form of calcite or amorphous calcium carbonate, deposited within the chitin-protein matrix [16,18-21].In the direction normal to the surface (the z-direction), as shown in Fig. 1b, there are well-developed, high-density pore canals containing long, flexible tubules penetrating through the exoskeleton. These tubules play an important role in the transport of ions and nutrition during the formation of the new exoskeleton after the animals molt [22]. The mechanical properties of crustacean exoskeletons (mud crab, Scylla serrata and prawn, Penaeus mondon) were first investigated by Hepburn et al. [23] and Joffeet al. [24]. Melnick et al. [25] studied the hardness and toughness of exoskeleton of the Florida stone crab, Menippe mercenaria, which exhibits a dark color (ranging from amber to black) on the chelae (tips of the claw) and walking legs. The dark material was much harder and tougher than the light-colored material from the same crab chela. The most comprehensive study is the one by Raabe and co-workers on the American lobster, Homarus americanus [11,26-30]. In this review, the mechanical properties of the sheep crab exoskeleton in the longitudinal direction (the $\mathrm{y}$-direction) and the z-direction were measured. The exoskeleton is highly anisotropic, both in structure and mechanical properties. The sheep crab (Loxorhynchun randis), which resides in California and Baja California, was used there. The sheep crab can reach a maximum span of $1 \mathrm{~m}$ and a mass of about $4 \mathrm{~kg}$ [31,32]. The relatively large size and thick exoskeleton (the average thickness in the merus (top section) of the walking legs is about 2.5 $\mathrm{mm}$ ) enable the mechanical tests in the z-direction. The motivation for this investigation is the establishment of the mechanisms by which nature develops strong and tough materials using relatively weak (chitin, proteins and calcium carbonate) constituents. A range of hard natural materials has been investigated, such as the intricate tiled structure of the nacreous component of abalone shells [33-35], the sandwich structure of toucan beaks [36,37], silk and others [7], yielding results that have significant technological applications. 


\section{MATERIALS AND METHODS}

Hepburn et al. [23] and Po-Yu Chen et al [38] worked a lot for crab exoskeleton. Hepburn et al. [23] used all test specimens from live crabs, Scylla serratu, caught on the southern Mozambique coast. Specimens were cut from the inner and outer flat areas of the meropodites of the larger walking legs. Specimens were tested in fresh condition and in the dehydrated state. Uniform specimens of conventional dumb-bell shape were used in all tensile mechanical tests using a tensometer especially designed for delicate bio-materials [5]. The rate of extension used was 33 $\mu \mathrm{m} / \mathrm{min}$ which corresponded to actual strain rates of about $.7 \% / \mathrm{min}$. In addition to tensile testing, dynamic measurements were also made of the elastic modulus by means of a vibrational resonance technique[39] and the torsional rigidity modulus was determined from measurements of the frequency of torsional vibrations [40]. Full details of the above procedures are described elsewhere [5]. Micro-hardness measurements were performed on whole crab shell with a Reichert Universal Camera Microscope "MeF" Microhardness Tester fitted with a diamond pyramidal indenting device.

Po-Yu Chen et al [38] used Three living adult male sheep crab, $15.4 \pm 0.8 \mathrm{~cm}$ in carapace width, were obtained from a local seafood market. The crabs were in intermolt stage, in which the exoskeleton is completely developed and fully mineralized [16,41]. They were then kept in a 150 gallon tank with constant circulation of fresh sea water (mean temperature $16^{\circ} \mathrm{C}$, mean salinity $33.60 \mathrm{ppt}$ ) and fed with fish weekly at the Scripps Institution of Oceanography until specimens were required. The tank was curtained, limiting the exposure to exterior lighting, creating a similar ambience to their natural habitat. Sample preparation was done as stated in the NIH Guide for Care and Use of Laboratory Animals. The microstructure was characterized using a field emission scanning electron microscope (SEM) equipped with EDS (FEI-XL30, FEI Company, Oregon, USA). Samples were prepared as cross-sections and sections parallel to the surface. Both samples were cut from the ventral merus of the first walking leg. For the crosssectional sample, a rectangular piece were obtained and then fractured in the longitudinal direction. For samples parallel to the surface, cylindrical pucks, $3 \mathrm{~mm}$ in diameter, were drilled using a diamond coring drill and fractured in tension. Samples were fractured immediately before examination with the SEM. The fractured samples were mounted on aluminum sample holders, air dried for 5 min and coated with $10 \mathrm{~nm}$ of gold in a sputter coater (Denton Discovery 18 Sputtering System, Denton Vacuum Inc., New Jersey, USA). Samples were observed with the secondary electron (SE) mode at $20 \mathrm{kV}$ accelerating voltage. Two sets of cross-sectional specimens (a total of six specimens from three different crabs) were prepared for microindentation. One was cut from the dorsal propodus (middle section) of the claw and the other was cut from the dorsal propodus of the second walking leg. The sample size was approximately $20 \mathrm{~mm} \times 5 \mathrm{~mm} \times 2 \mathrm{~mm}$ (length, width and thickness, respectively). Samples were mounted in epoxy with the cross-sectional area revealed, then ground and finely polished (Fig. 2a). A hardness testing machine (LECO M-400-H1, Leco Co., Michigan, USA) equipped with a Vickers indenter was used. A load of $0.245 \mathrm{~N}$ was applied for $15 \mathrm{~s}$, and a further $45 \mathrm{~s}$ was allowed to elapse before the diagonals of the indentation were measured. Twelve indentations were made through the thickness of exoskeleton at $100 \mu \mathrm{m}$ intervals and 10 parallel series of tests were performed on each sample (giving a total of 120 indentations). 

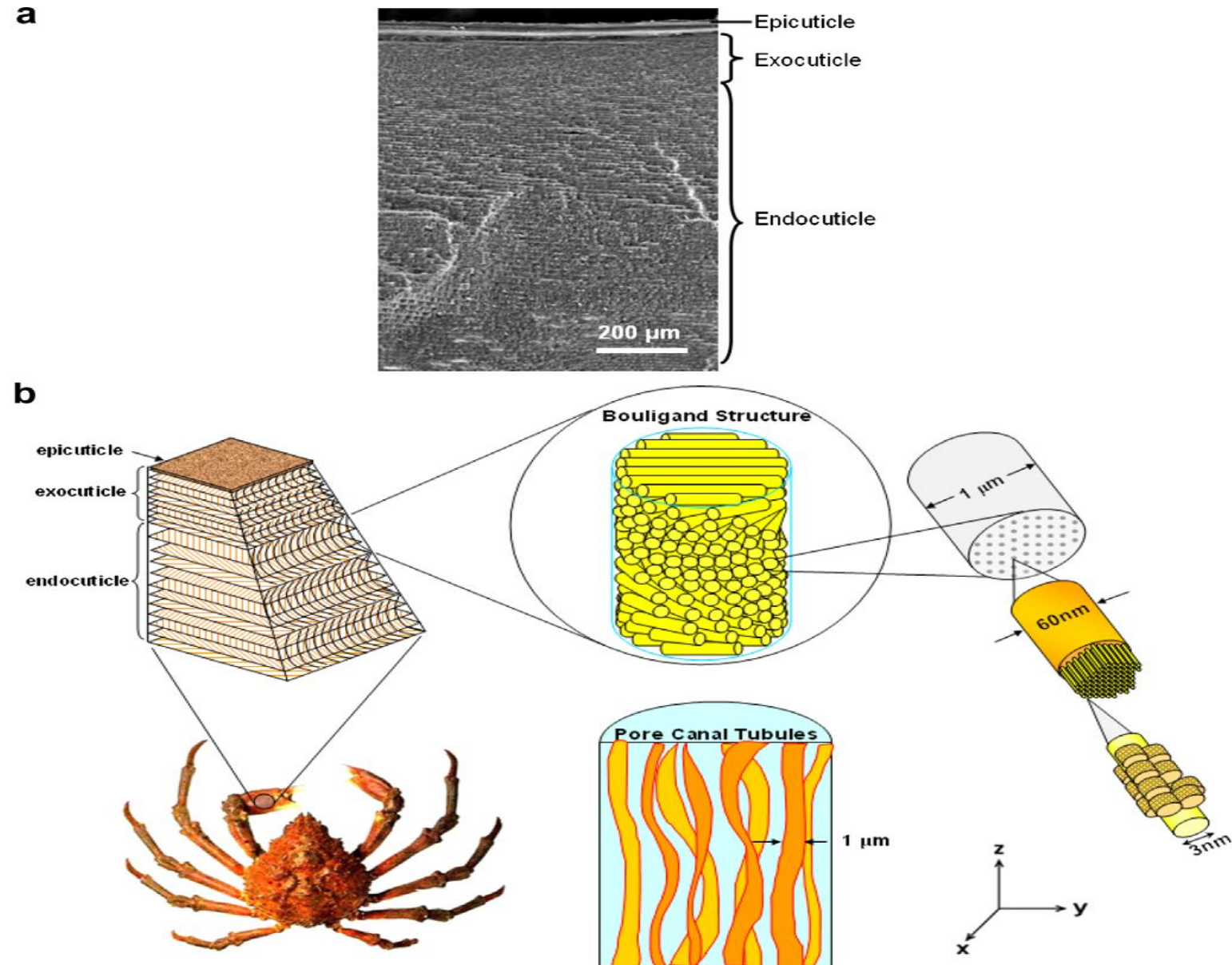

Figure 1 (a) SEM micrograph of a cross-sectional fracture surface showing three different layers in the exoskeleton: epicuticle, exocuticle, and endocuticle. (b) Hierarchical structure of the exoskeleton of sheep crab, Loxorhynchus grandis. Chitin fibrils (_3 nm in diameter) wrapped with proteins form a fiber of _60 nm in diameter. Fibers further assemble into bundles, which form horizontal planes $(x-y$ plane $)$ superposed in a helicoid stacking, creating a twisted plywood structure (180_ rotation). In the z-direction there are ribbonlike tubules, $1 \mathrm{~lm}$ wide and $0.2 \mathrm{~lm}$ thick, running through the pore canals.

Specimens used for tensile and compressive testing in the longitudinal direction were taken from the merus of the first and second pairs of walking legs (Fig. 2). Tensile testing was carried out in the longitudinal direction of the crab walking legs, whereas tensile testing in the transverse direction was not conducted due to the limitation of sample size and curvature (the merus of walking legs is tubular in shape, about $12 \mathrm{~cm}$ in length and $2 \mathrm{~cm}$ in diameter). After muscle removal, the specimens were dissected into rectangles approximately $3 \mathrm{~cm}$ in length and $1 \mathrm{~cm}$ in width. The rectangles were ground to a thickness of about $1.8 \mathrm{~mm}$ and subsequently inserted into a laser cutting machine; the dog-bone shape, which was programmed into the machine, had a length of $25.4 \mathrm{~mm}$, width of $6.35 \mathrm{~mm}$, gage length of $6.35 \mathrm{~mm}$ and gage width of $2.29 \mathrm{~mm}$. Thirty-four pieces were cut from three different crabs to prepare two equal sets of samples, one in a dry condition and one wet. Seventeen samples were air-dried, while others were kept in seawater to prevent desiccation during preparation. However, this could not be done for an 
indefinite period since the exoskeleton would become completely demineralized after several days. Therefore, for the hydrated condition, the testing was carried out within $24 \mathrm{~h}$ after the specimens were obtained. The tensile tests in the longitudinal direction were performed on a specially designed fixture, consisting of two symmetric grips confined by a guiding track on the side. The grips were machined and had the same geometry as the dog-bone-shaped sample. The lower grip was fixed while the upper grip was movable and attached to a universal testing machine. The grips were designed in such a manner that the force was distributed evenly on the ends of specimens and this ensured that failure occurred in the reduced section. The grip design used also shielded specimens from bending, which could affect the results. A universal testing machine (Instron 3346 Single Column Testing Systems, Instron, MA, USA) equipped with a 500 $\mathrm{N}$ load cell was used. . Tensile testing was also carried out in the direction perpendicular to the surface (z-direction) as shown in Fig. 2c. Fifteen cylindrical pucks, $3.12 \mathrm{~mm}$ in diameter, were cut from the exoskeleton using a diamond coring drill. The epicuticle layer on the surface was removed leaving the exocuticle and endocuticle. The thickness of the samples is $2.50 \pm 0.12 \mathrm{~mm}$. These pucks were glued onto platens using J-B Weld_epoxy resin (J-B Weld Company, Texas, USA) and allowed to cure for $24 \mathrm{~h}$. The platens were gripped to the universal testing machine and tested at a $0.03 \mathrm{~mm} / \mathrm{min}$ crosshead speed. The fracture first occurred at the exocuticleendocuticle interface. The exocuticle region was removed after fracture, leaving only the endocuticle region. Because the thickness of exocuticle is less than $200 \mu \mathrm{m}$, restricting the tensile testing, only the endocuticle region $(2.48 \pm 0.11 \mathrm{~mm}$ thick) was achievable. Compressive testing was conducted on the cylindrical samples in the z-direction (Fig. 2d). Two sets of samples, one in a dry condition and the other wet, were tested. A universal testing machine (Instron 3367 Dual Column Testing Systems, Instron, Massachusetts, USA) equipped with a 30 $\mathrm{kN}$ load cell was used. The dimensions of samples were summarized in Tables 1-3.
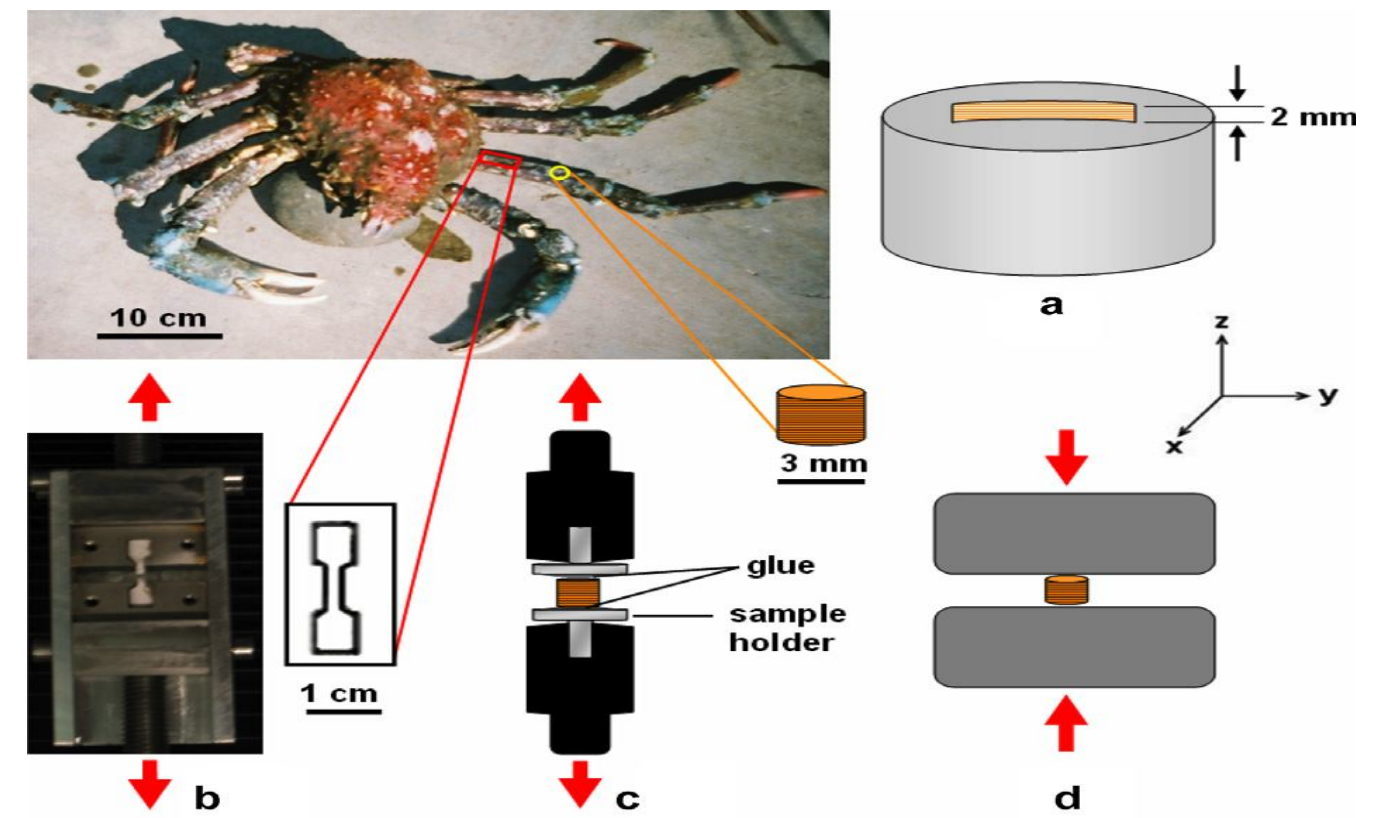

Figure 2 Schematic representation of mechanical tests: (a) micro indentation hardness test; (b) tensile test in the longitudinal direction; (c) tensile test in the z-direction; (d) compressive test in the z-direction. 
Table 1 Mechanical properties of crab exoskeletons from tensile testing in the longitudinal direction

\begin{tabular}{|c|c|c|c|c|c|c|c|c|}
\hline Sample & $\mathbf{n}$ & $\mathbf{l}(\mathbf{m m})$ & $\begin{array}{l}\mathbf{W} \\
(\mathrm{mm})\end{array}$ & $\mathrm{t}(\mathrm{mm})$ & $\begin{array}{l}\mathrm{E} \\
\text { (MPa) }\end{array}$ & $\begin{array}{l}\mathbf{r f} \\
(\mathbf{M P a})\end{array}$ & ef $(\%)$ & $\begin{array}{l}\text { Toughness } \\
\text { (MPa) }\end{array}$ \\
\hline $\begin{array}{l}\text { Sheep } \\
\text { crab wet }\end{array}$ & 17 & $\begin{array}{ll}6.35 & \pm \\
0.01 & \end{array}$ & $\begin{array}{l}2.29 \\
\text { 0.03 }\end{array}$ & $\begin{array}{l}1.81 \\
0.09\end{array}$ & $\begin{array}{ll}518 & \pm \\
72 & \end{array}$ & $\begin{array}{l}31.5 \quad \pm \\
5.4\end{array}$ & $\begin{array}{ll}6.4 & \pm \\
1.0 & \\
\end{array}$ & $1.02 \pm 0.25$ \\
\hline $\begin{array}{l}\text { Sheep } \\
\text { crab dry }\end{array}$ & 17 & $\begin{array}{ll}6.35 & \pm \\
0.01 & \end{array}$ & $\begin{array}{ll}2.29 & \pm \\
0.03 & \\
\end{array}$ & $\begin{array}{l}1.81 \pm \\
0.10\end{array}$ & $\begin{array}{ll}764 & \pm \\
83 & \\
\end{array}$ & $\begin{array}{ll}12.9 & \pm \\
1.7 & \end{array}$ & $\begin{array}{l}1.8 \pm \\
0.3\end{array}$ & $0.11 \pm 0.03$ \\
\hline $\begin{array}{l}\text { Mud crab } \\
\text { wet [17] }\end{array}$ & & & & & $\begin{array}{ll}481 & \pm \\
75 & \end{array}$ & $\begin{array}{ll}30.1 & \pm \\
5.0 & \\
\end{array}$ & 6.2 & \\
\hline $\begin{array}{l}\text { Mud crab } \\
\text { dry [17] }\end{array}$ & & & & & $\begin{array}{l}640 \pm \\
89\end{array}$ & $\begin{array}{ll}23.0 & \pm \\
3.8 & \end{array}$ & 3.9 & \\
\hline
\end{tabular}

The properties are the average including their standard deviation: 1, gage length; $w$, gage width; $t$, thickness; E, Young's modulus.

rf, stress to fracture; and ef, strain to fracture

Table 2 Mechanical properties of crab exoskeletons from tensile testing in the z-direction

\begin{tabular}{|c|c|c|c|c|c|c|c|}
\hline Sample & n & $\mathbf{d}(\mathbf{m m})$ & $\mathbf{t}(\mathrm{mm})$ & E (MPa) & $\begin{array}{l}\text { rf } \\
\text { (MPa) }\end{array}$ & ef $(\%)$ & $\begin{array}{l}\text { Toughness } \\
\text { (MPa) }\end{array}$ \\
\hline Exo/endocuticle & 15 & $\begin{array}{ll}3.12 & \pm \\
0.09 & \end{array}$ & $\begin{array}{ll}2.50 & \pm \\
0.12 & \end{array}$ & $511 \pm 79$ & $9.4 \pm 2.6$ & $\begin{array}{ll}2.0 & \pm \\
0.4 & \end{array}$ & $0.11 \pm 0.04$ \\
\hline Endocuticle & 15 & $\begin{array}{l}3.12 \pm \\
0.08\end{array}$ & $\begin{array}{ll}2.48 & \pm \\
0.11 & \end{array}$ & $536 \pm 87$ & $\begin{array}{ll}19.8 & \pm \\
3.0 & \end{array}$ & $\begin{array}{ll}6.4 & \pm \\
1.6 & \end{array}$ & $0.78 \pm 0.30$ \\
\hline
\end{tabular}

The properties are the average values including their standard deviation: $d$, diameter; $t$, thickness; E, Young's modulus.

rf, stress to fracture; and ef, strain to fracture.

Table 3Mechanical properties of crab exoskeletons from compressive testing in $\mathrm{z}$-direction

\begin{tabular}{|c|c|c|c|c|c|c|c|}
\hline Sample & $\mathbf{n}$ & $\mathrm{d}(\mathbf{m m})$ & $\mathrm{t}(\mathrm{mm})$ & E (MPa) & rf (MPa) & ef $(\%)$ & $\begin{array}{l}\text { Toughness } \\
\text { (MPa) }\end{array}$ \\
\hline $\begin{array}{l}\text { Sheep } \\
\text { crab wet }\end{array}$ & 17 & $\begin{array}{ll}3.11 & \pm \\
0.11 & \end{array}$ & $\begin{array}{ll}2.49 & \pm \\
0.09 & \end{array}$ & $634 \pm 63$ & $101 \pm 11$ & $\begin{array}{ll}15.7 & \pm \\
2.7 & \end{array}$ & $8.3 \pm 1.5$ \\
\hline $\begin{array}{l}\text { Sheep } \\
\text { crab dry }\end{array}$ & 17 & $\begin{array}{ll}3.12 & \pm \\
0.10 & \end{array}$ & $\begin{array}{l}2.49 \\
0.12\end{array}$ & $\begin{array}{l}1069 \pm \\
96\end{array}$ & $57 \pm 10$ & $5.2 \pm 1.2$ & $1.6 \pm 0.5$ \\
\hline
\end{tabular}

The properties are the average values including their standard deviation: d, diameter; $t$, thickness;

E, Young's modulus.

rf, stress to fracture; and ef, strain to fracture. 


\section{RESULTS AND DISCUSSION}

Hepburn et al. [23] did the experiments on specimens of untreated whole crab shell. Wet shell has a breaking stress of $30.14 \pm 5 \mathrm{MPa}$ and an elastic modulus of $481 \pm 75 \mathrm{MPa}$ while dry crab has a breaking stress of 23.01 3.8 MPaand a modulus of $640 \pm 89 \mathrm{MPa}$. A typical tensile stressstrain curve for both wet and dry crab is shown in Fig. 3. The curve demonstrates that both wet and dry whole crab shell exhibits a unique discontinuity in the region of low strain This same discontinuity has been observed for whole prawn shells[42]. However, the bulk tensile stressstrain behavior of isolated crab chitin, prawn chitin [42], regenerated chitin [42], beetle chitin [43]; [2]Hepburn \& Ball, 1973) as well as from various insect solid cuticles[2,3,4] is completely free even of any suggestion of such a discontinuity. As in the case of whole prawn shell [24] the occurrence of this discontinuity is associated with the tensile failure of the inorganic salt phase of the skeletons. This salt matrix is extremely brittle and consequently, when specimens of whole shell are stretched, brittle failure of the salt phase occurs at low strain resulting in the characteristic discontinuity and leaving the still intact chitin and protein phases to bear the load. This interpretation gains additional support from the fact that torsional rigidity measurements could not be carried out due to the extreme brittleness of this material. Interpretations of the properties of bio-materials are hampered by a number of parameters that could not be measured by available technology, such as inter-lamellar binding strengths and friction, Poisson's ratio and interactions between the various phases, etc. Hence the possible influence of many factors remains unknown. Similarly, other parameters which can be measured are biologically obscure. Such is the case with indentation microhardness, an index of the material's resistance to plastic indentation. Micro-indentations of about $25 \mu \mathrm{m}$ depth were made and measured on the external surfaces of samples of dry whole cuticle taken from the outer and inner sides of the meropodites after it was noticed during handling that the two sides of the segment were tangibly different. The outer portion of the leg yielded an average value of 81.06 \pm 16.6 MPawhile the inner leg cuticle was $82.21 \pm 18.8 \mathrm{MPa}$, values which are not significantly different. The relative microhardness is therefore the same on both external surfaces of the leg despite differences in cuticular thickness and apparent tangible rigidity. Failure of both wet and dry whole crab shell occurs sharply at the ultimate breaking stress and there is no detectable plastic deformation of these materials.. The tensile failure of crab shell differs substantially from the fracture behaviour of prawn shells in which there is a clear delamination of the exocuticle from the endocuticle as well as endocuticular sub-delamination[5] and insect cuticles[2,3,4]. Since there is a sharp increase in the elastic moduli of crab shell on drying, as in other arthropod shells, it is concluded that under normal functional use during life, cuticular water considerably reduces the en-brittling effects of the inorganic salt phase. It would appear then that a live wet cuticle is a composite material which exhibits both reasonable flexibility and adequate strength and toughness. One might speculate on the role of the three phases as they operate in the composite shell. Such a composite would have been designed for great compressive strength and the role of the inorganic salt phase would be to supply this compressive strength as a sort of concrete. The chitinous skeleton would supply tensile strength (useful in bending) while the protein phase is probably present as a reinforcement for the inorganic phase and possibly giving rise to a prestressed type of material once sclerotization of the protein is complete. Since the operational criteria for these shells are not known, it is not possible to state to what extent the actual shell represents an optimization of design; however, the evolutionary longevity of arthropod cuticle suggests that this construction is a more than adequate solution to skeletal design. 


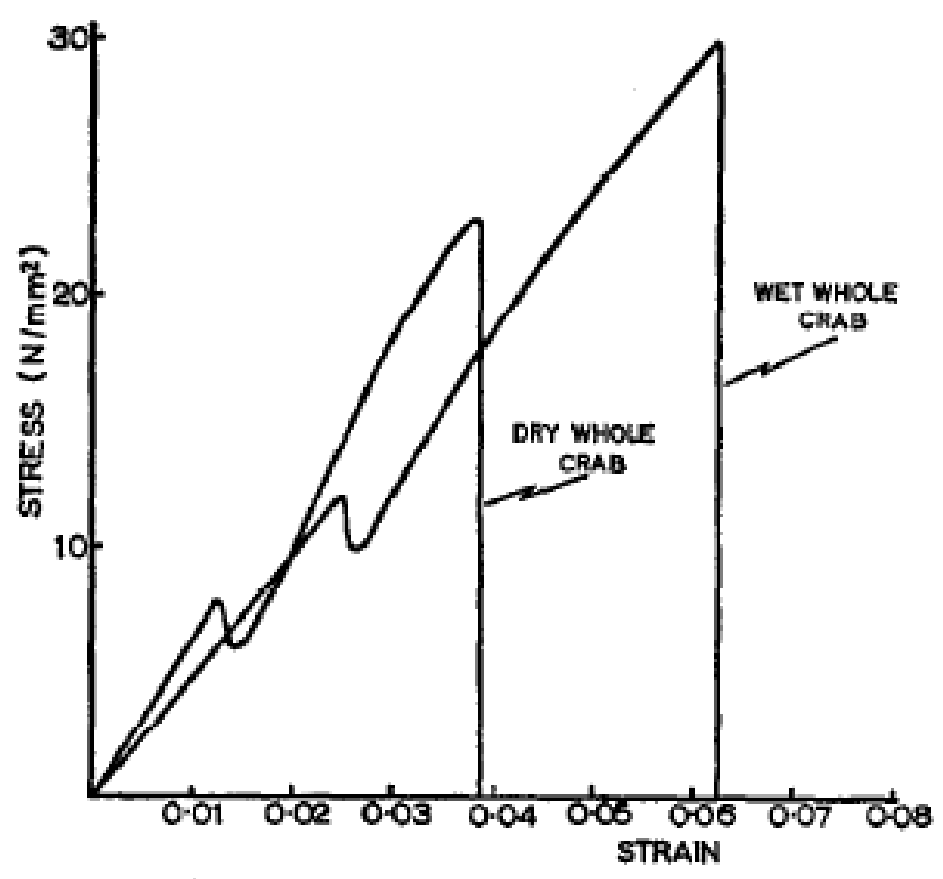

Figure 3 Typical tensile stress-strain curves for wet and dry whole crab cuticle with low strain discontinuities

Fig. 4 shows the micro indentation hardness through the thickness of the crab claws and walking legs[38]. The data points are the average of 30 tests from three different samples and the scale bars are the standard deviations. The scanning electron micrograph of a cross-section is also shown in conjunction with the results. There is a discontinuity of hardness across the interface between the exocuticle and the endocuticle for both samples. The hardness values are $947 \pm 74$ $\mathrm{MPa}$ for claws and $247 \pm 19 \mathrm{MPa}$ for walking legs at $100 \mathrm{~mm}$ depths from the surface, which is in the exocuticle region (approximately $200 \mathrm{~mm}$ thick). They drop to a much lower value, $471 \pm$ $50 \mathrm{MPa}$ for claws and $142 \pm 17 \mathrm{MPa}$ for walking legs in the endocuticle (_2.5 mm thick). Thus, the hardness value in the exocuticle is about twice higher than that in the endocuticle. The discontinuity in hardness through the thickness of the crab exoskeleton is analogous to the results from American lobster (H. americanus) [11,28]. A qualitative energy-dispersive X-ray (EDX) mapping for calcium was carried out at the interface between the exocuticle and endocuticle of the American lobster [28]. The result reveals a gradient in the calcium content between the exocuticle and endocuticle, indicating the exocuticle is more highly mineralized. Such design (higher hardness and wear resistance on the surface) is widely used in nature. For example, mammalian teeth are composed of external enamel and internal dentine. Enamel is hard and highly mineralized, while dentine is tougher and contains 30 vol.\% of collagen. Another example is the smashing limb of the mantid shrimp, Gonodactylus chiragra, studied by Currey and co- 
workers [46]. The outer layer has a heavily calcified cuticle, with a significant amount of calcium carbonate being replaced by calcium phosphate. Beneath the outer layer is a fibrous region which absorbs the kinetic energy and prevents cracks from propagating through the cuticle. The smashing limb is well designed to break hard-shelled prey. Another interesting discovery from the results is that the hardness values of the claw are about 3-4 times higher than those of the walking legs. The mineral content of the sheep crab exoskeleton was determined by heating a specimen at $400^{\circ} \mathrm{C}$ for $8 \mathrm{~h}$, and measuring the remaining ash weight. The average ash content of 15 pieces from the propodus of claws is $79.3 \pm 4.9 \%$ of dry weight. The average ash content of 15 pieces from the merus of walking legs is $61.9 \pm 3.7 \%$ of dry weight. The much higher hardness of the claw is likely due to the higher mineral content. The hardness values measured in this work are higher than those of the American lobster claw (130-270 MPa in exocuticle and 30-55 $\mathrm{MPa}$ in endocuticle) [11]. This may also relate to the higher mineral content in sheep crab compared with the American lobster, which has an ash content of $63.6 \pm$ $4.3 \%$ of dry weight [47]

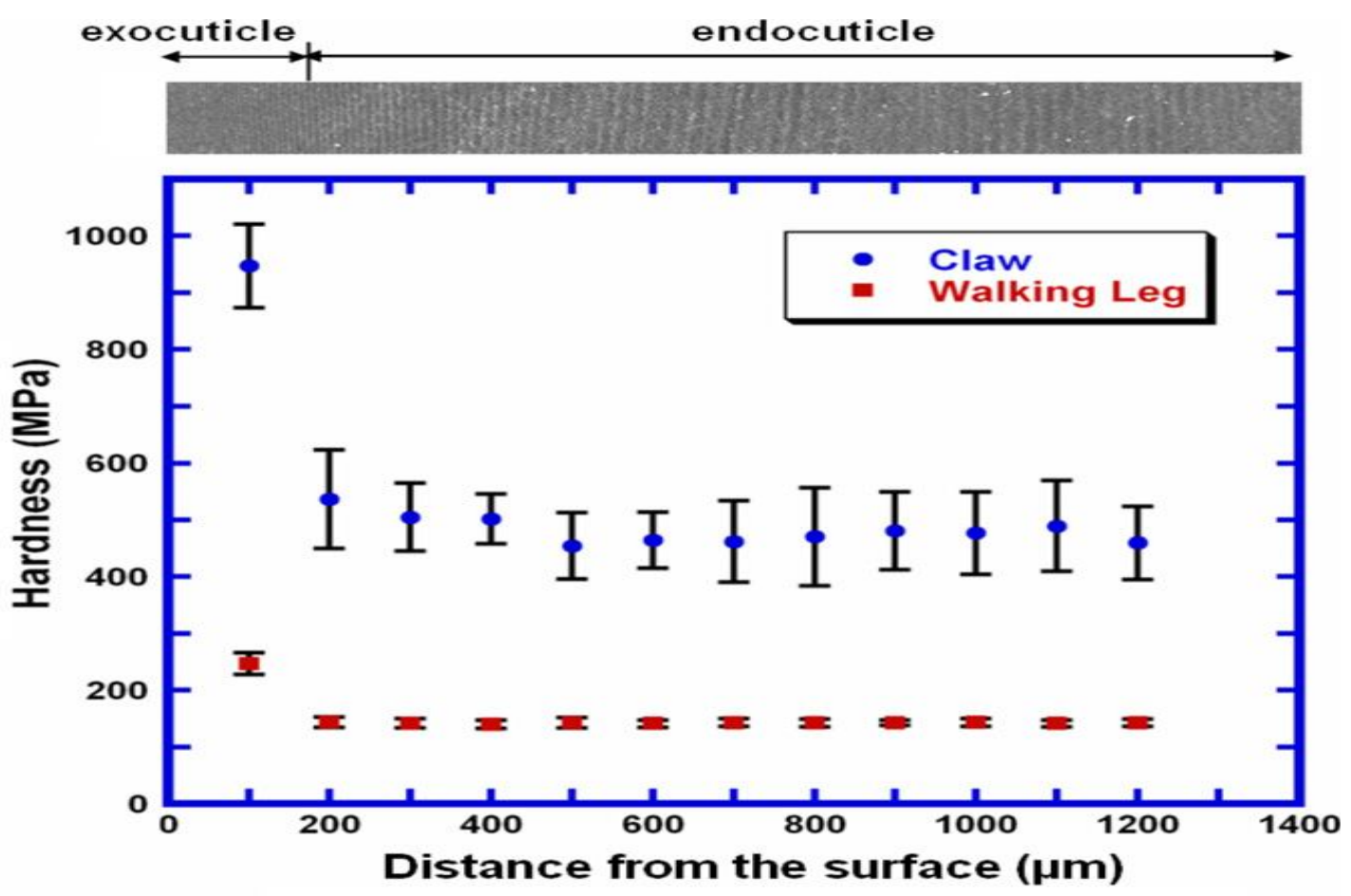

Figure 4 Microindentation hardness showing a discontinuity through the thickness of crab claws and walking legs (data point: average; scale bar: standard deviation). The SEM micrograph above the plot documents the location where indentations were taken.

Fig. 5 shows the typical stress-strain curves in the dry and wet conditions. They exhibit a slightly convex shape stress-strain response which corresponds to elastic deformation. Table 1 summarizes the mechanical properties of 34 tests taken from three different crabs[38]. The wet samples have an average ultimate tensile strength of $31.5 \pm 5.4 \mathrm{MPa}$ at an average strain to 
fracture of $6.4 \pm 1.0 \%$. The dry samples break at an average ultimate tensile strength of $12.9 \pm$ 1.7 $\mathrm{MPa}$ at an average strain to fracture of $1.8 \pm 0.3 \%$. The stress-strain curves for wet samples are not perfectly linear. This may be due to sample alignment at the initial stage. The Young's modulus was measured by taking the data points after $2 \%$ of strain and linear fitting. The average value of Young's modulus for the wet samples was $518 \pm 72 \mathrm{MPa}$, whereas it was $764 \pm 83 \mathrm{MPa}$ for the dry samples. The work-of-fracture or toughness, as measured by the area under the stress- strain curve, is significantly affected by gradual fracture. The toughness for wet samples is $1.02 \pm 0.25 \mathrm{MPa}$, which is almost 10 times higher than that for dry samples, which is $0.11 \pm$ $0.03 \mathrm{MPa}$. Hepburn and co-workers [23] investigated the mechanical properties of mud crab, S. serrata, in tension. There is a load drop in stress-strain curves at low strain. Hepburn et al. [23] concluded that this may due to the failure of inorganic minerals at low strain, followed by the fracture of chitin-protein matrix. However, the discontinuity is not observed in Po-Yu Chen et al [38].

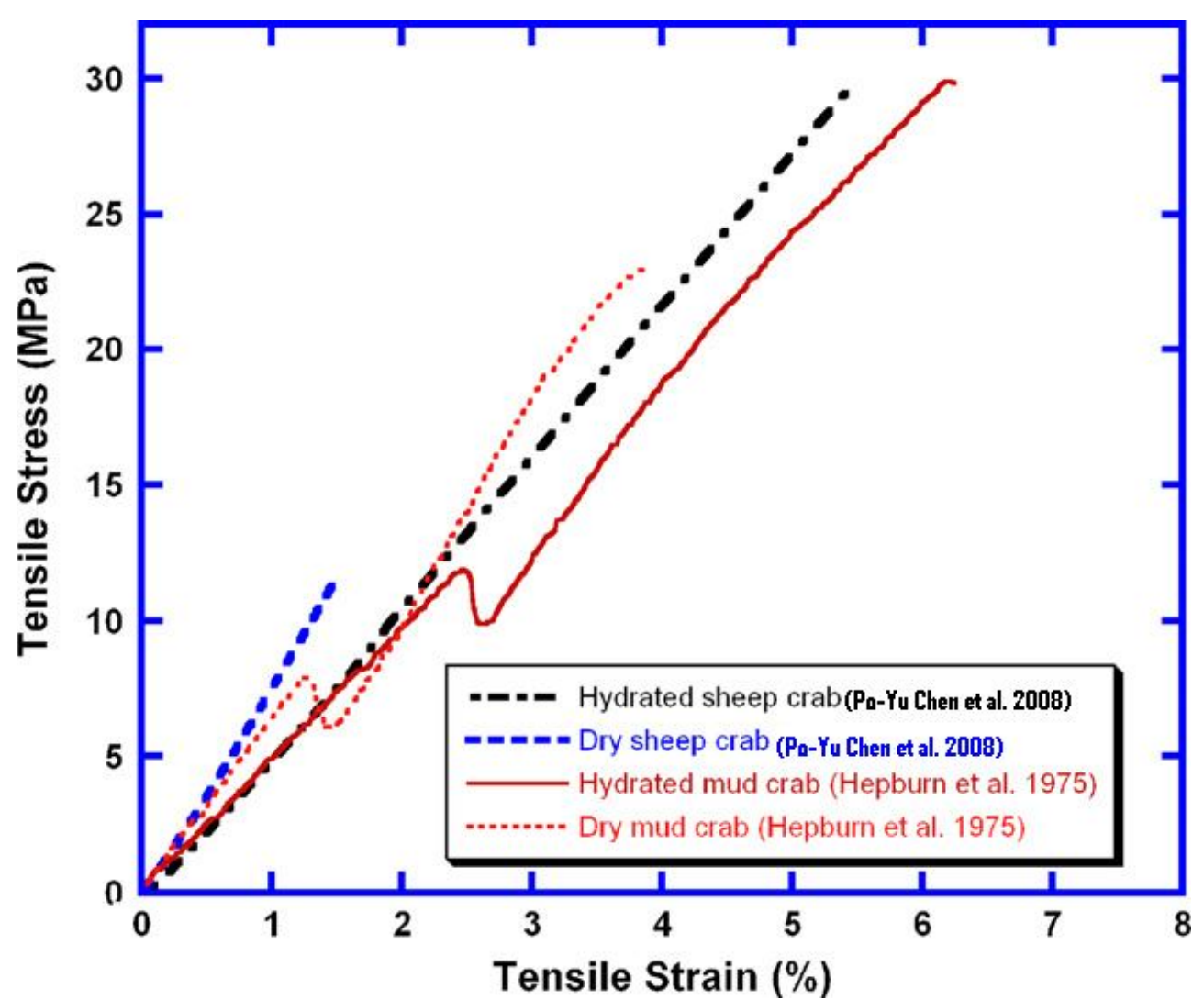

Figure 5 Typical tensile stress-strain response of sheep crab exoskeleton in both dry and wet states in the ydirection. The results are compared with the mud crab exoskeleton by Hepburn et al. [23].

Fig. 6 shows the results of tensile testing in the z-direction and mechanical properties are summarized in Table 2. For the cylindrical puck containing both exocuticle and endocuticle, the stress-strain curve is linear and fracture occurs at $9.4 \pm 2.6 \mathrm{MPa}$ and $2.0 \pm 0.4 \%$ strain. For the sample that contains only endocuticle layers, the stress-strain curve shows a non-linear plastic deformation and the ultimate tensile strength reaches $19.8 \pm 3.0 \mathrm{MPa}$ and $6.4 \pm 1.6 \%$ strain. The elastic modulus is $511 \pm 79 \mathrm{MPa}$ for exo/endocuticle samples and is $536 \pm 87 \mathrm{MPa}$ for endocuticle samples. The toughness of the sample containing both exocuticle and endocuticle is 
$0.11 \pm 0.04 \mathrm{MPa}$. For the sample containing only endocuticle, the toughness is much higher, reaching $0.78 \pm 0.30 \mathrm{MPa}$.

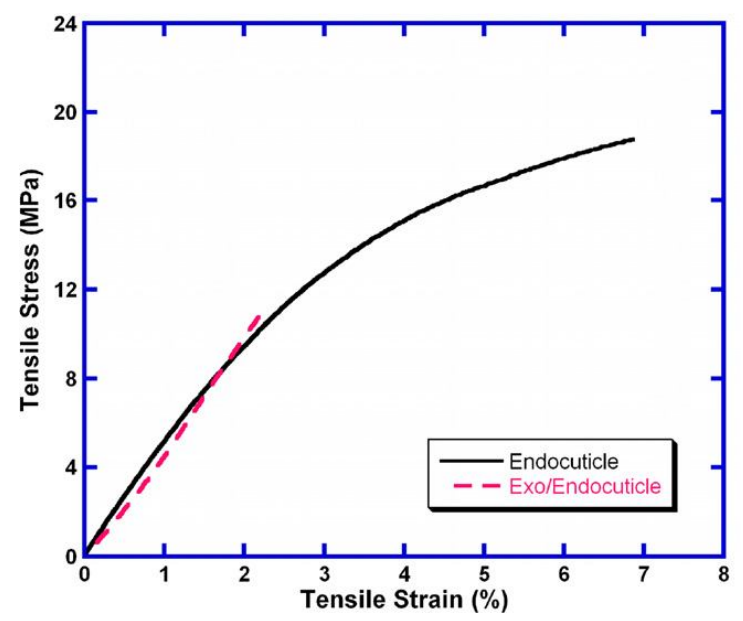

Figure 6 Typical tensile response of sheep crab exoskeleton in the zdirection (dry condition).

Fig. 7 shows typical stress-strain curves in compression for both wet and dry crab exoskeletons in the z-direction. The results are summarized in Table 3. For wet samples, the average value of yield strength and Young's modulus are $101 \pm 11$ and $634 \pm 63 \mathrm{MPa}$, respectively. For dry samples, average yield strength and Young's modulus are $57 \pm 10 \mathrm{MPa}$ and $1.07 \pm 0.10 \mathrm{GPa}$, respectively. Compressive strength can be predicted from the Vickers hardness value, Hv, as $\mathrm{rc}=$ $\mathrm{Hv} / 3$. The average hardness of crab walking legs (in a dry condition) is $151 \pm 30 \mathrm{MPa}$, corresponding to a predicted compressive strength of about $50 \mathrm{MPa}$, which is slightly lower than the measured value $(57 \pm 10 \mathrm{MPa})$. Both the strength and stiffness are higher in compression than in tension. The average toughness value of wet samples is $8.3 \pm 1.5 \mathrm{MPa}$, whereas that of dry samples is $1.6 \pm 0.5 \mathrm{MPa}$.

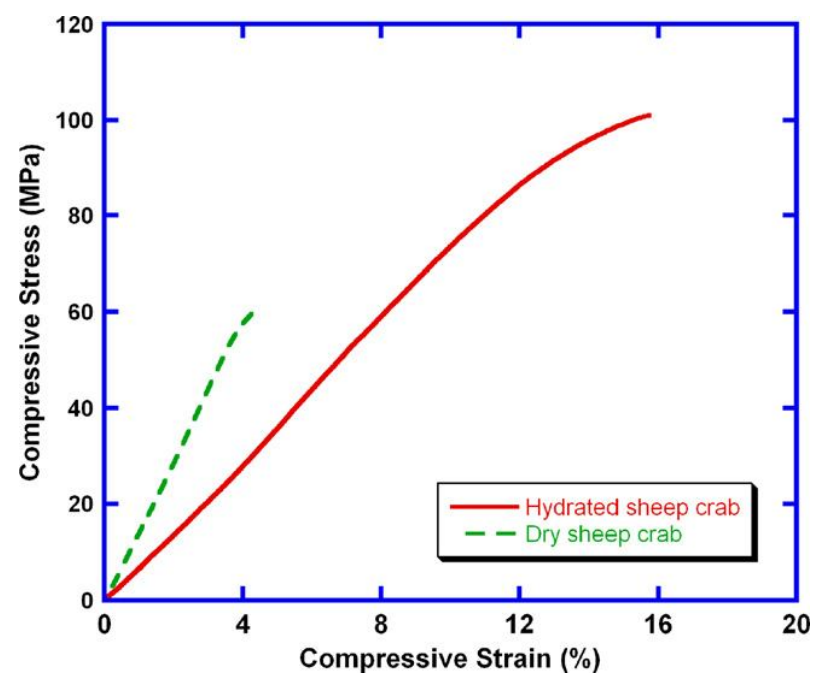

Figure 7 Typical compressive stress-strain response of sheep crab exoskeleton in the z-direction (dry and wet conditions) 


\section{CONCLUSIONS}

The present review investigates the various mechanical properties of the crab shell. Different type of crab shells are used for experimentation. The results of the review show that the under tensile loading conditions it is seen that whole crab shell exhibits a mode of fracture which does not include the delamination of lamellae common to the other arthropods thus far studied. Whole crab shell does, however, show the low strain discontinuity previously seen for prawn cuticle but absent from insect cuticle. The inference is that the three-phase crustacean cuticles which share the discontinuity in the bulk tensile stress-strain curve are uniquely different from the insect cuticles which lack the third, inorganic salt phase. However, once the crustacean cuticle is stretched beyond the point at which the inorganic salt phase fails, the load-bearing properties and behaviour of the remaining two phases of the crustacean shells are virtually identical to those of the insects. The crab exoskeleton is a three-dimensional composite comprising brittle chitinprotein bundles arranged in a Bouligand pattern (the $\mathrm{x}-\mathrm{y}$ plane) and ductile pore canal tubules in the direction normal to the surface (the zdirection). The pore canal tubules possess ductile mechanical properties even in a dry condition. The Bouligand layers in exocuticle have a dense structure (3-5 $\mu \mathrm{m}$ each layer) and high hardness (947 MPa in claws and $247 \mathrm{MPa}$ in walking legs). The endocuticle has a more open structure (10-15 $\mu \mathrm{m}$ each layer) and lower hardness (471 $\mathrm{MPa}$ in claws and $142 \mathrm{MPa}$ in walking legs). The predicted compressive strength from hardness tests $(50 \mathrm{MPa})$ is slightly lower than the measured values (57 MPa) by Po- Yu chen 2008. The presence of water plays in important role in the mechanical properties. For both tensile and compressive tests, the wet samples have higher strength and toughness than the dry samples The high density of pore canal tubules which fail in the ductile mode may play an important role in enhancing toughness in the z-direction. It is important for materials scientists to understand the design of natural composites, in order to develop novel composite materials with enhanced properties. The review completely explains the progress of study of crab shell conducted by various scientists. The review of mechanical properties with structure analysis is hereby proposed.

\section{REFERENCES}

[1] Jensenm. \& Weis-Foght (1962) Biology and physics of locust flight-V. Strength and elasticity of locust cuticle. Phil. Trans. $R$. Sot., B245. 137-169.

[2] Hepburn H. R. \& Ball A. (1973) On the structure and mechanical properties of beetle shells. J. mat. Sci. 8, 618-623.

[3] Hepburn H. R. \& Joffe I. (1974a) Hardening of locust sclerites. J. Insect Physiol. 20, 631-635.

[4] Hepburn H. R. \& Joffe I. (1974b) Locust solid cuticle-a time sequence of mechanical properties. J. Insect Physiol. 20, 497-506.

[5] Joffe I. \& Hepburn H. R. (1974) A simple low-cost tensometer for bio-materials testing. Experientia. 30, 113-14.

[6] Neville AC. Biology of the arthropod cuticle. New York: Springer- Verlag; 1975.

[7] Vincent JFV. Structural biomaterials. Princeton, NJ: Princeton University Press; 1991.

[8] Vincent JFV. Arthropod cuticle: a natural composite shell system. Composites A 2002;33:1311-5.

[9] Vincent JFV, Wegst UGK. Design and mechanical properties of insect cuticle. Arthropod Struct Dev 2004;33:187-99.

[10] Sanchez C, Arribart H, Giraud-Guille MM. Biomimetism and bioinspiration as tools for the design of innovative materials and systems. Nat Mat 2005;4:277-88.

[11] Raabe D, Sachs C, Romano P. The crustacean exoskeleton as an example of a structurally and mechanically graded biological nanocomposite material. Acta Mater 2005;53:4281-92. 
[12] Bouligand Y. Twisted fibrous arrangements in biological materials and cholesteric meso phases. Tissue Cell 1972;4:189-217.

[13] Giraud-Guille MM. Fine structure of the chitin-protein system in the crab cuticle. Tissue Cell 1984;16:75-92.

[14] Giraud-Guille MM. Chitin crystals in arthropod cuticles revealed by diffraction contrast transmission electron microscopy. J Struct Biol 1990;103:232-40.

[15] Weiner S, Addadi L. Design strategies in mineralized biological materials. J Mater Chem 1997;7:689-702.

[16] Roer R, Dillaman R. The structure and calcification of the crustacean cuticle. Am Zool 1984;24:893-909.

[17] Giraud-Guille MM. Plywood structure in nature. Curr Opin Solid State Mater Sci 1998;3:221-8.

[18] Lowenstam HA. Minerals formed in organisms. Science 1981;211:1126-31.

[19] Mann S, Webb J, Williams RJP. On biomineralization. New York: VCH; 1989.

[20] Lowenstam HA, Weiner S. On biomineralization. New York: Oxford University Press; 1989.

[21] Giraud-Guille MM, Bouligand Y. Crystal growth in a chitin matrix: the study of calcite development in the crab cuticle. In: Karnicki ZS, Brzeski PJ, Wojtasz-Pajak A, editors. Chitin World. Bremerhaven: Wirtschaftsverlag NW; 1994. p 136-144.

[22] Cameron JN. Post-molt calcification in the blue crab, Callinectes sapidus - timing and mechanism. J Exp Biol 1989;143:285-304.

[23] Hepburn HR, Joffe I, Green N, Nelson KJ. Mechanical properties of a crab shell. Comp Biochem Physiol 1975;50A:551-4.

[24] Joffe I, Hepburn HR, Nelson KJ, Green N. Mechanical properties of a crustacean exoskeleton. Comp Biochem Physiol 1975;50A:545-9.

[25] Melnick CA, Chen S, Mecholsky JJ. Hardness and toughness of exoskeleton material in the stone crab Menippe mercenaria. J Mater Res 1996;11:2903-7.

[26] Raabe D et al. Discovery of a honeycomb structure in the twisted plywood patterns of fibrous biological nanocomposite tissue. J Cryst Growth 2005;283:1-7.

[27] Raabe D et al. Structure and crystallographic texture of arthropod bio-composites. Mater Sci Forum 2005;495-497:1665-74.

[28] Raabe D et al. Microstructure and crystallographic texture of the chitin-protein network in the biological composite material of the exoskeleton of the lobster Homarus americanus. Mater Sci Eng A2006;421:143-53.

[29] Sachs C, Fabritius H, Raabe D. Hardness and elastic properties of dehydrated cuticle from the lobster Homarus americanus obtained by nanoindentation. J Mater Res 2006;21:1987-95.

[30] Romano P, Fabritius H, Raabe D. The exoskeleton of the lobster Homarus americanus as an example of a smart anisotropic biological material. Acta Biomater 2007;3:301-9.

[31] Jensen GC. Pacific Coast Crabs and Shrimps. Monterey: Sea Challengers; 1995.

[32] Debelius H. Crustacea: Guide of the World. Frankfurt: IKAN- Unterwasserarchiv; 2001.

[33] Menig R, Meyers MH, Meyers MA, Vecchio KS. Quasi-static and dynamic mechanical response of Haliotis rufescens (abalone) shells. Acta Mater 2000;45:2389-98.

[34] Mayer G. Rigid biological systems as models for synthetic composites. Science 2005;310:1144-7.

[35] Mayer G. New classes of tough composite materials - lessons from nature rigid biological systems. Mater Eng Sci C 2006;26:1261-8.

[36] Seki Y, Schneider MS, Meyers MA. Structure and mechanical properties of the toucan beak. Acta Mater 2005;53:5281-96.

[37] Seki Y, Kad B, Benson D, Meyers MA. The toucan beak: structure and mechanical response. Mater Sci Eng C 2006;26:1412-20.

[38] Altman GH et al. Silk-based biomaterials. Biomaterials 2003;24:401-16.

[39] Worsnop B. L. \& Flint H. T. (1961) Advanced Practical Physics, 9th edn). Methuen, London.

[40] HEARMON R. F. S. \& BARKAS W. (1941) The effect of grain direction on the Young's moduli and rigidity moduli of beech and sitka spruce. Proc. Phys. Sot. 53,674-680.

[41] Drach P. Mue et cycle d'intermue chez les crustace'e' decapods. Ann Inst Oceanogr 1939;19:103-391.

[42] JOFFE I. \& HEPBURN H. R. (1973) Observations on regenerated chitin. J. materials Sci. 8, 1751-1754.

[43] HEPBURN H. R. (1972) Some mechanical properties of crossed fibrillar chitin. J. Insect PhysioL 18, 815825.

[44] Hegdahl T, Silness J, Gustavsen F. The structure and mineralization of the carapace of the crab (Cancer pagurus L) - 1. The endocuticle. Zool Scr 1977;6:89-99.

[45] Roer RD. Mechanisms of resorption and deposition of calcium in the carapace of the crab Carcinus maenas. J Exp Biol 1980;88:205-18. 
[46] Currey JD, Nash A, Bonfield W. Calcified cuticle in the stomatopod smashing limb. J Mater Sci 1982;17:1939-44.

[47] Hayes DK, Armstrong WD. The distribution of mineral material in the calcified carapace and claw shell of the American lobster, Homarus americanus, evaluated by means of microroentgenograms. Bio Bull $1961 ; 121: 307-15$ 